\title{
Structural Study of $\mathrm{CHCl}_{3}$ Molecular Assemblies in Micropores Using X-ray Techniques
}

\author{
TAKU IIYAMA ${ }^{1}$, YOSHIE KOBAYASHI ${ }^{1}$, ATSUSHI MATSUMOTO², \\ YOSHITAKA NAKAHIGASHI ${ }^{2}$ AND SUMIO OZEKI ${ }^{1}$ \\ ${ }^{1}$ Department of Chemistry, Faculty of Science, Shinshu University, 1-33 Asahi, Matsumoto 390-8621, Japan \\ ${ }^{2}$ Ad'all Co., Ltd., 5 Tonouchi, Uji, Kyoto 611-8555, Japan \\ tiiyama@shinshu-u.ac.jp \\ nakahigashi@adall.co.jp \\ sozeki@shinshu-u.ac.jp
}

\begin{abstract}
The X-ray diffraction from $\mathrm{CHCl}_{3}$ molecules adsorbed in slit-shaped micropores of activated carbon fibers were measured at $298 \mathrm{~K}$. The pore effect on structure of molecular assemblies in the graphitic micropores was examined. The peak positions due to the first nearest neighbor $\mathrm{CHCl}_{3}$ in the electron radial distribution function of adsorbed phase agreed with those of bulk liquid, although their peak intensities were different. In narrow pores (pore width $w=1.1 \mathrm{~nm}$ ), the peak intensities due to the first nearest molecule are stronger than the bulk liquid, because a peak due to the correlation between carbon walls and $\mathrm{CHCl}_{3}$ molecules was overlapped. In the wider pores of ACF W10 $(w=1.3 \mathrm{~nm})$ having high $\mathrm{CHCl}_{3}$ removal efficiency from tap water, the intensity of the peak of $r=0.4 \mathrm{~nm}$ is the strongest. It suggests that $\mathrm{CHCl}_{3}$ molecules in the $1.3 \mathrm{~nm}$ micropores should be orientated for a $\mathrm{Cl}$ atom to meet with a carbon atom in wall surfaces. These results demonstrate that the structure of a polar molecule such as $\mathrm{CHCl}_{3}$ will sensitively be subject to micropore effects.
\end{abstract}

Keywords: $\quad \mathrm{CHCl}_{3}$ (chloroform), microporous carbon, $\mathrm{XRD}$, radial distribution function, dipole

\section{Introduction}

The behavior of molecules confined in small space has attracted much attention. These molecules show the special phenomena such as unique phase transition and ordered structure formation (liyama et al., 1997a). One of origins of these phenomena is the fact that the adsorbed phase is constituted by small number of molecules.

The analysis method for adsorbed phases in the micropore in molecular level is limited, because the micropore space is surrounded by the solid. Since X-ray can penetrate various materials, we can detect directly the structural information on adsorbed phase itself in micropore with the X-ray techniques. The information of intermolecular structure among adsorbed molecules can be obtained by in situ X-ray diffraction (XRD) measurement. In previous studies, we showed by using this method that water molecules form a solid-like structure in the carbon micropore even at room temperature (liyama et al., 1995). On the other hand, small angle X-ray scattering (SAXS) can provide the information about shape and size of adsorbed molecular assemblies (Iiyama et al., 2000). The density fluctuation of adsorption systems changes with adsorption which molecules fill empty pores. We reported that the density fluctuation and correlation length from SAXS can directly translate to the size of both 
adsorbed molecular assemblies and vacant (Iiyama et al., 2004).

In this paper, we report adsorption state of $\mathrm{CHCl}_{3}$ in carbon micropore using in situ XRD. Filling states of $\mathrm{CHCl}_{3} \mathrm{molecules}$ in the micropores are governed by the molecule-surface and intermolecular interactions, which should be quite sensitive to the pore width and shape. The behavior of a polar $\mathrm{CHCl}_{3}$ molecule in the hydrophobic space is interesting from the scientific viewpoint. On the other hand, $\mathrm{CHCl}_{3}$ is a carcinogen, and the removal from tap water is strongly desired. The adsorption method using microporous materials is the most effective method for $\mathrm{CHCl}_{3}$ removal from water containing very small amount (Chang et al., 1997). We try to determine the intermolecular structure of $\mathrm{CHCl}_{3}$ assemblies in the carbon micropore, and the relation of the assembly structure with $\mathrm{CHCl}_{3}$ removal efficiency of activated carbons is discussed.

\section{Experimental}

Two kinds of pitch-based activated carbon fibers (ACFs; Ad'all Co.), A20 and W10, were used as adsorbents. Two ACF samples have different porosities. W10 has 5 times greater $\mathrm{CHCl}_{3}$ removal efficiency than $\mathrm{A} 20$ in the water flow condition. The micropore structures of these samples were determined by $\mathrm{N}_{2}$ adsorption at $77 \mathrm{~K}$ after pre-heating at $383 \mathrm{~K}$ and $1 \mathrm{mPa}$ for $2 \mathrm{~h}$. The $\mathrm{CHCl}_{3}$ adsorption isotherms were determined at $298 \mathrm{~K}$ by a volumetric method.

The XRD profiles from $\mathrm{CHCl}_{3}$ adsorbed samples at $298 \mathrm{~K}$ were measured with the transmission method by use of an angle-dispersion diffractometer (Rigaku, AFC-5R) with Mo K $\alpha$ radiation. The scattering parameter $s(s=4 \pi \sin \theta / \lambda$, where $2 \theta$ and $\lambda$ are the scattering angle and the wave length of X-ray, respectively) ranging from $s=7$ to $120 \mathrm{~nm}^{-1}$ was covered. The XRD profiles were corrected by an appropriate method, and the scattering intensity from adsorbed $\mathrm{CHCl}_{3}$ assembly was extracted from the XRD profiles corrected by subtraction the diffraction data of carbon itself. The experimental setup and extracting methods were already published in the previous article (liyama et al., 1997b).

The electron radial distribution function (ERDF) analysis for the amorphous structure (Warren, 1934) was applied to adsorbed $\mathrm{CHCl}_{3}$ molecular assembly in the micropore. The ERDF, $4 \pi r^{2}\left(\rho(r)-\rho_{0}\right)$, is obtained by the Fourier transformation of the extracted XRD profiles. Here $\rho(r)$ and $\rho_{0}$ are the density at a distance $r$ and the average density, respectively. The ERDF expresses the local molecular structure of adsorbed $\mathrm{CHCl}_{3}$ by the distribution of the electron density.

\section{Results and Discussion}

$\mathrm{N}_{2}$ adsorption isotherms at $77 \mathrm{~K}$ were of Type I. The micropore volume $W_{0}\left(\mathrm{~N}_{2}\right)$ and specific surface areas $a_{\alpha}$ are shown in Table 1. The external surface area is negligibly small compared with $a_{\alpha}$. We assumed the slit-shaped pore because the pore wall had been composed of the graphite crystallite. The average pore widths $w$ estimated from both of $a_{\alpha}$ and $W_{0}\left(\mathrm{~N}_{2}\right)$ are also shown in Table 1. The average pore widths of A20 and W10 correspond to the 1.9 and 2.2 adsorbed layers, respectively.

\begin{tabular}{cccc} 
Table 1. & The pore structure of ACF samples by $\mathrm{N}_{2}$ adsorption at $77 \mathrm{~K}$. \\
& Micropore volume & Surface area & Pore width \\
& $W_{0}\left(\mathrm{~N}_{2}\right) / \mathrm{mLg}^{-1}$ & $a_{\alpha} / \mathrm{m}^{2} \mathrm{~g}^{-1}$ & $w / \mathrm{nm}$ \\
\hline A20 & 1.01 & 1770 & 1.1 \\
W10 & 0.50 & 760 & 1.3 \\
\hline
\end{tabular}


The adsorption isotherms of $\mathrm{CHCl}_{3}$ on ACF at $298 \mathrm{~K}$ are shown in Figure 1 . The ordinate is expressed by the fractional filling of $\mathrm{CHCl}_{3}, \phi=v / v_{0}$, where $v$ and $v_{0}$ are volume of adsorbed $\mathrm{CHCl}_{3}$ and that of saturated condition, respectively. They are also Type I. The initial uptakes in A20 were much greater than W10. The isotherm for W10 showed the significant hysteresis around $P / P_{0}=0.35$, indicating some portion of $\mathrm{CHCl}_{3}$ filled by capillary condensation in mesopores. The micropore volumes from $\mathrm{CHCl}_{3}$ adsorption, $W_{0}\left(\mathrm{CHCl}_{3}\right)$ were estimated using the density of bulk liquid $\mathrm{CHCl}_{3}\left(\rho_{\mathrm{CHCl}}=1.49 \mathrm{~g} \mathrm{ml}^{-1}\right)$. The volume ratio $W_{0}\left(\mathrm{CHCl}_{3}\right) / W_{0}\left(\mathrm{~N}_{2}\right)$ of $\mathrm{A} 20$ and $\mathrm{W} 10$ were 1.05 and 1.15. The positive deviation from unity suggests a dense packing of adsorbed $\mathrm{CHCl}_{3}$ molecules.

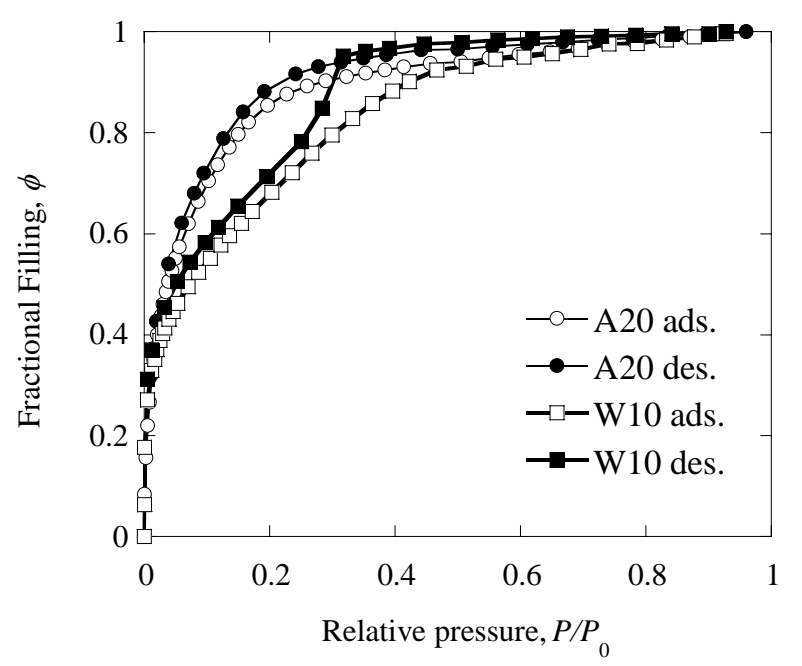

Figure 1. Adsorption isotherms of $\mathrm{CHCl}_{3}$ on ACF samples at 298K.
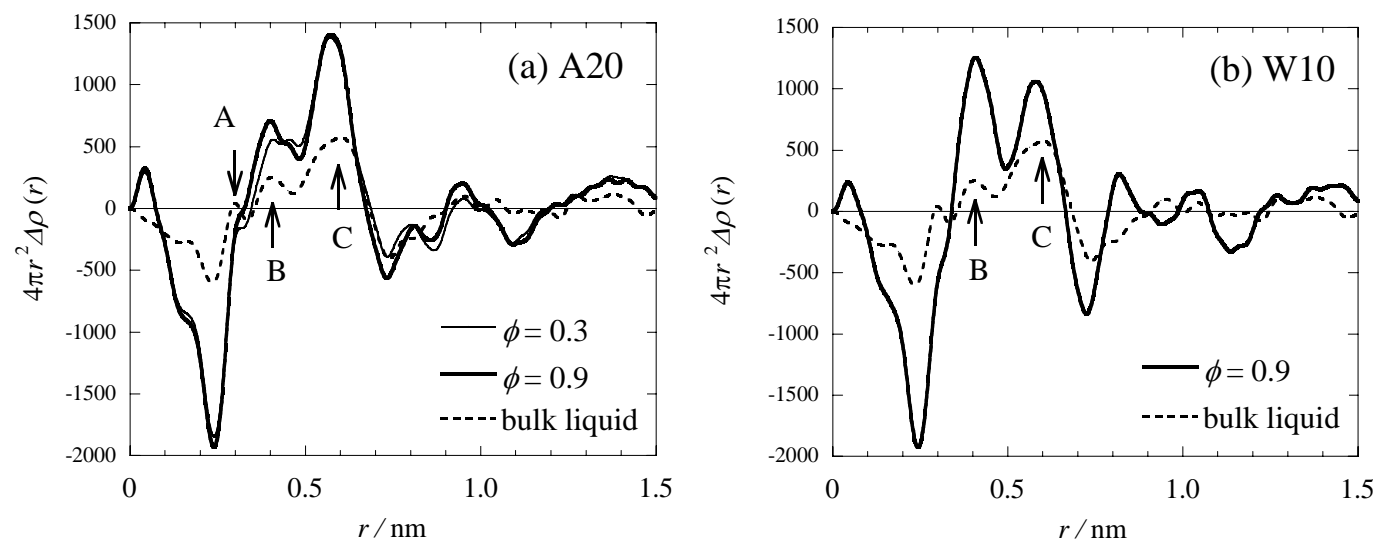

Figure 2. The ERDF of $\mathrm{CHCl}_{3}$ adsorbed in micropores and bulk liquid $\mathrm{CHCl}_{3}$ at 298K. (a) A20, (b) W10. Broken lines are for bulk liquid of $\mathrm{CHCl}_{3}$. 
Figure 2(a) shows the ERDF of $\mathrm{CHCl}_{3}$ adsorbed in micropores of $\mathrm{A} 20$ at $298 \mathrm{~K}$ and $\phi=0.3$ and 0.9 . For comparison, the ERDF of bulk liquid $\mathrm{CHCl}_{3}$ is also shown in Figure 2 for comparison. The ERDF of bulk $\mathrm{CHCl}_{3}$ shows the characteristic peaks at $0.30 \mathrm{~nm}(\mathrm{~A})$, at $0.40 \mathrm{~nm}(\mathrm{~B})$, and at $0.61 \mathrm{~nm}(\mathrm{C})$, which are attributed to, respectively, $\mathrm{H}-\mathrm{Cl}, \mathrm{Cl}-\mathrm{Cl}$ (near side), $\mathrm{Cl}-\mathrm{Cl}$ (far side) distances of the nearest neighbor $\mathrm{CHCl}_{3}$ (Bertagnolli and Chieux, 1980; Bertagnolli, 1981). The peak positions for ERDF of adsorbed state agree with that of bulk liquid, indicating that the adsorbed $\mathrm{CHCl}_{3}$ has a similar structure to bulk liquid. However, the intensities of peaks $\mathrm{B}$ and $\mathrm{C}$ are much stronger than these of bulk liquid. The strong peaks suggest that an ERDF peak at around $0.3-0.6 \mathrm{~nm}$, which arises from the interference between $\mathrm{CHCl}_{3}$ molecules and carbon wall, should overlap with $\mathrm{Cl}-\mathrm{Cl}$ peaks. The distance $0.45 \mathrm{~nm}$ was the center-to-center distance between an adsorbed $\mathrm{CHCl}_{3}$ molecule and a carbon atom at pore wall, since a $\mathrm{CHCl}_{3}$ molecule is regarded as a sphere of the $0.58 \mathrm{~nm}$ diameter (Israelachvili, 1991a). Moreover, decrease in the mobility of $\mathrm{CHCl}_{3}$ adsorbed may cause increase in the amplitude of ERDF. The ERDFs of adsorbed $\mathrm{CHCl}_{3}$ at $\phi=0.3$ and 0.9 agreed with each other in the whole $r$ range. It is considered that $\mathrm{CHCl}_{3}$ molecule adsorbed in the micropore form cluster-like assembly by lateral interaction between ad-molecules even at low $\phi$ region.

Figure 2(b) shows the ERDF of $\mathrm{CHCl}_{3}$ adsorbed at $\phi=0.9$ in the W10 system. The ERDF curve has similar features to the A20 case, but the intensity of peak B is the strongest, different from the A20 system (in which peak C is the strongest). This feature suggests a special orientation of $\mathrm{CHCl}_{3}$ molecule in $\mathrm{W} 10$ systems. We estimated the interference term between carbon wall and adsorbed $\mathrm{CHCl}_{3}$ assuming several geometrical arrangements. Figure 3 shows the two configurations of a $\mathrm{CHCl}_{3}$ molecule on a graphite surface: in Model A, three $\mathrm{Cl}$ atoms contact with a carbon wall and on Model $\mathrm{B}$, two $\mathrm{Cl}$ atoms and an $\mathrm{H}$ atom contact with the wall. These configurations may give theoretical interference term in the ERDF (Prins and Peterson, 1936). The both models it is inferred that gave the largest peak at $0.40 \mathrm{~nm}$, but the peak in Model A was larger than that in Model B. Therefore, $\mathrm{CHCl}_{3}$ adsorbed in $\mathrm{W} 10$ should be oriented as Model A.
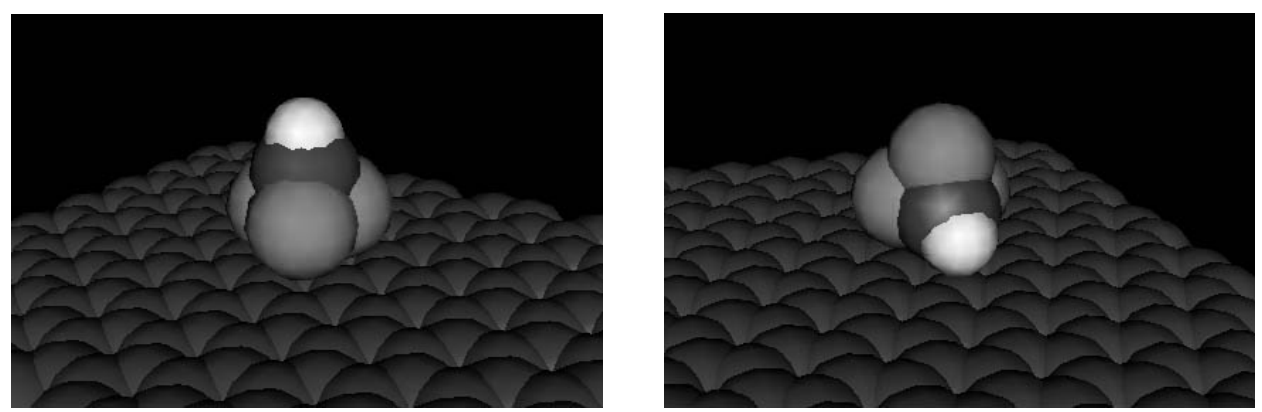

Model A

Model B

Figure 3. The configuration models of adsorbed $\mathrm{CHCl}_{3}$.

These results show that the structure of adsorbed $\mathrm{CHCl}_{3}$ assemblies sensitively responds to the micropore structure. This seems to originate from the facts that $\mathrm{CHCl}_{3}$ is polar and its diameter close to the pore width. Though $\mathrm{CHCl}_{3}$ is adsorbed by mainly dispersion force with the carbon surface, the structure of adsorbed phase seems to be influenced by the dipole-dipole interaction. The maximum dipole-dipole attraction occurs when two dipoles are lying in line $(\longrightarrow)$, which is twice as much as while for two dipoles aligned parallel to each other $(\uparrow \downarrow)$ (Israelachvili, 1991b). It is known that the bulk liquid of $\mathrm{CHCl}_{3}$ contains the structure in which the dipoles lying in line (Bertagnolli, 1981). However, in the carbon pores, another structure may be stabilized, because the micropores can be considered almost two-dimensional space. It was shown by the computer simulation and $\mathrm{XRD}$ measurements that in the $\mathrm{CCl}_{4}$-carbon micropore system the $\mathrm{CCl}_{4}$ structure sensitively changed with 
micropore width in the range of 1 to 2 molecular diameters (liyama et al., 1997b; Suzuki et al., 1999). In the $\mathrm{CHCl}_{3}-\mathrm{W} 10$ system, the adsorbed molecules form ordered structure in which the dipole stands in vertical to the carbon surface and an anti-parallel side-by-side order. In this arrangement, the mirror potential should also effectively works (Wang et al., 1995). It is considered that the intermolecular interaction in $\mathrm{CHCl}_{3}$ assemblies in the micropores should lead to the high $\mathrm{CHCl}_{3}$ removal efficiency of W10.

\section{References}

Bertagnolli, H. and Chieux, P., Ber. Bunsenges. Phys. Chem., 84, 1225-1231 (1980).

Bertagnolli, H., Ber. Bunsenges. Phys. Chem., 85, 644 (1981).

Chang, T-M., Dang, L. X., Peterson, K. A., J. Phys. Chem. B, 101, 3413-3419 (1997).

liyama, T., Nishikawa, K., Otowa, T. and Kaneko, K., J. Phys. Chem., 99, 10075-10076 (1995).

liyama, T., Nishikawa, K., Suzuki, T. and Kaneko, K., Chem. Phys. Lett., 274, 152-158(1997a).

liyama, T., Nishikawa, K., Suzuki, T., Otowa, T., Hijiriyama, M., Nojima, Y. and Kaneko, K., J. Phys. Chem. B, 101, 3037-3042 (1997b).

liyama, T., Ruike, M. and Kaneko, K., Chem. Phys. Lett., 331, 359-364 (2000).

liyama, T., Kobayashi, Y., Kaneko, K. and Ozeki, S., J. Coll. Surf. A, in press (2004).

Israelachvili, J., Intermolecular and surface forces, $2^{\text {nd }}$ Ed., pp. 109-111, Academic Press, London (1991a).

Israelachvili, J., Intermolecular and surface forces, $2^{\text {nd }}$ Ed., pp. 57-60, Academic Press, London (1991b).

Prins, J. A. and Petersen, H., Physica, 3, 147 (1936).

Suzuki, T., liyama, T., Gubbins, K. E. and Kaneko, K., Langmuir, 15, 5870-5875 (1999).

Wang, Z. M. and Kaneko, K., J Phys. Chem., 99, 16714 (1995)

Warren, B.E. and Gingrich, N. S., Phys. Rev., 46368 (1934). 